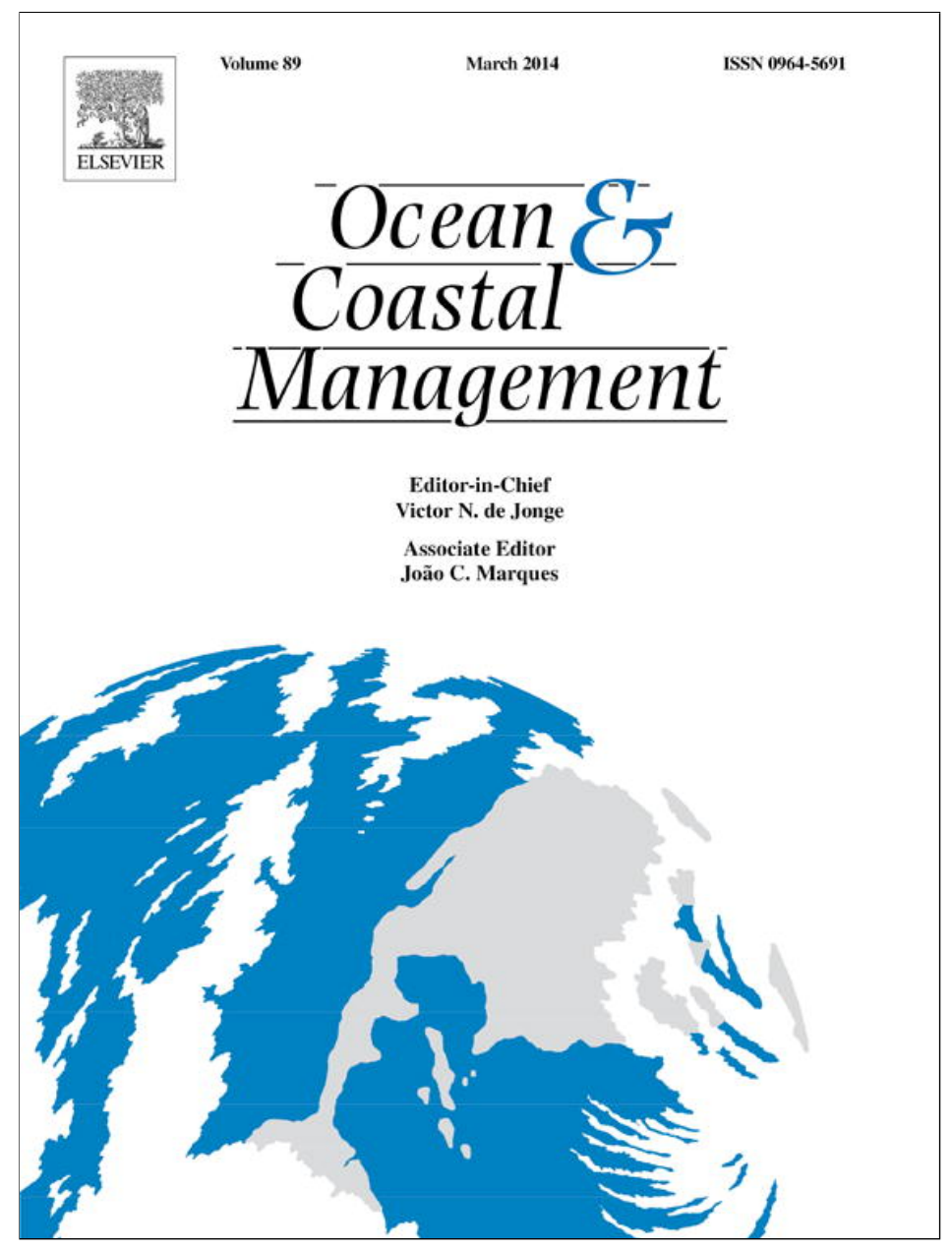

This article appeared in a journal published by Elsevier. The attached copy is furnished to the author for internal non-commercial research and education use, including for instruction at the authors institution and sharing with colleagues.

Other uses, including reproduction and distribution, or selling or licensing copies, or posting to personal, institutional or third party websites are prohibited.

In most cases authors are permitted to post their version of the article (e.g. in Word or Tex form) to their personal website or institutional repository. Authors requiring further information regarding Elsevier's archiving and manuscript policies are encouraged to visit: 


\title{
Marine and river environments: A pattern of Integrated Coastal Zone Management (ICZM) in Calabria (Southern Italy)
}

\author{
Nicola Cantasano*, Gaetano Pellicone \\ National Research Council, Institute for Agricultural and Forest Systems in the Mediterranean, Via Cavour 4/6, 87036 Rende, CS, Italy
}

\section{A R T I C L E I N F O}

\section{Article history:}

Available online 9 January 2014

\begin{abstract}
A B S T R A C T
The integrated coastal zone management is a working and continuous process to promote a dynamic balance between economic growth, human use of natural resources and environmental protection of coastal systems. The integration between terrestrial and marine environments is the main purpose of this course through a new kind of landscape planning extended from coastlines to continental areas, along the ideal lines of regional catchments. So, coastal environments require an integrated management to establish mutual interactions between human, political and scientific elements to achieve a sustainable development of the coastal zone. In this study, it has been developed a specific methodological framework, named Function Analysis, applied to a littoral region located in a wilderness area. The results highlight the good environmental condition of this seaboard system exposed, however, to a definite human pressure. In fact, the ecological and human values, plotted in a diagram, point out a transition state, for the studied area, on the border between development and conservation plans. To solve this problem, it is hoped to improve the environmental value of the ecological and fluvial corridor of Verri stream basin connecting two terrestrial and marine Sites of Community Interest, as conservation is the higher priority for this coastal region. In conclusion, it has been suggested to manage marine and terrestrial resources through a coordinated strategy in which coastal and river environments could be, really, inserted in the same landscape unit to promote the social and economic development of local communities toward a sustainable development of coastal areas.
\end{abstract}

(C) 2013 Elsevier Ltd. All rights reserved.

\section{Introduction}

Coastal areas have long been recognized as a pole of development for mankind. Yet, apart from the great cultural value of human societies growing on littoral regions, the man-sea relationship has been always marked by human conflicts and social strains that are becoming especially heavy in these last decades. Indeed, the uncontrolled development of human activities on coastline has produced an overloading and, in some serious situations, an overcoming of the carrying capacities of coastal ecosystems. Moreover, according to the present trend of economic policy, the gradual decrease of some tertiary services, as fishery, has produced a clear increase in the rate of youth unemployment, the steady rise in migratory flow and a general state of socio-economic troubles. In this social context, the whole shortage of transport and communication networks has supported local conditions of social alienation and a general state of economic need for the resident

\footnotetext{
* Corresponding author. Tel.: +39 (0)984841404; fax: +39 (0)984466052.

E-mail address: cantasano@isafom.cs.cnr.it (N. Cantasano).
}

population living in littoral zones. However, the coastal region could be, nowadays, an important factor for a possible recovery of human societies and for the potential development of local economies owing to the large number of service industries confined to this narrow transition area between land and sea. Therefore, it is necessary to meet the various requirements related to human pressure in coastal areas, so to avoid possible social conflicts and to better manage the natural resources through an overall view of littoral regions, based on the following principles (Kelleher and Kenchington, 1990):

1. Holistic approach: connections between marine and terrestrial elements of coastal zones.

2. Accordance with natural processes: knowledge of natural dynamics of bio-chemical cycles in seaboard systems.

3. Adoption of balanced resolutions: resilience in managing coastal conflicts to assure outlooks for long.

4. Search of a public agreement in the planning steps: active involvement of stack-holders in the policy-making process.

5. Support and participation of central and local government in decision functions. 
6. Coordinated use of a set of economic, scientific and informative tools for a right coastal management.

According to these rules, the most effective means to limit the exploitation of marine resources and the deterioration of coastal environments are into taking strategic plans for protecting and improving the natural resources arranged in seaboard through a new pattern of Integrated Coastal Zone Management (hereafter ICZM) based on an ecosystem approach (Courtney and White, 2000; Olsen and Christie, 2000; McLeod and Leslie, 2009). By its meaning, ICZM is an active and continuous process to promote the sustainable development of coastal areas carrying out a dynamic balance between economic growth, human exploitation of natural resources and environmental protection (UN, 1992; Barcena, 1992). Then, a correct coastline management needs an overall view of the system directed in a deep integration among the following levels (CicinSain and Belfiore, 2005): sectorial $\leftrightarrow$ government $\leftrightarrow$ spatial $\leftrightarrow$ scientific $\leftrightarrow$ managerial. Indeed, coastline is a transition area between marine and terrestrial environments where these two basic elements must join altogether in the same landscape unit (van der Weide, 1993):

- the natural subsystem made by biotic and abiotic components;

- the socio-economic subsystem including all the human exploitations of the natural resources with the physical and social facilities produced by mankind.

So, coastal system becomes a real asset where these two dynamic elements are, mutually, controlled by natural boundary conditions and by socio-economic development plans (Fig. 1). In the middle of this pattern, ICZM takes a strategic and central position and it appears as the best tool to integrate a lot of inputs coming from different knowledge into an integrated management of coastal areas. In this way, the suggested pattern connects ecological, social and economic features to realize a real and effective accord between planning activities, coastal management and environmental quality, but also for supplying new social and economic chances to local communities.

One of the focus of this study is to provide an overview on European policy in the implementation of ICZM to protect and, if necessary, to restore ecological quality and integrity for Mediterranean seaboard. Somehow, ICZM suggests a new pattern of coastal management through which an effective integration between social structures, economic pattern and policy issues could realize and maintain a sustainable use of coastal resources. Taking into account the European experience, it has been analyzed, here, how ICZM programs could be implemented in Italy where the process is, still, in its first stages for the shortage of a national strategy and for the extreme fragmentation between the institutional powers

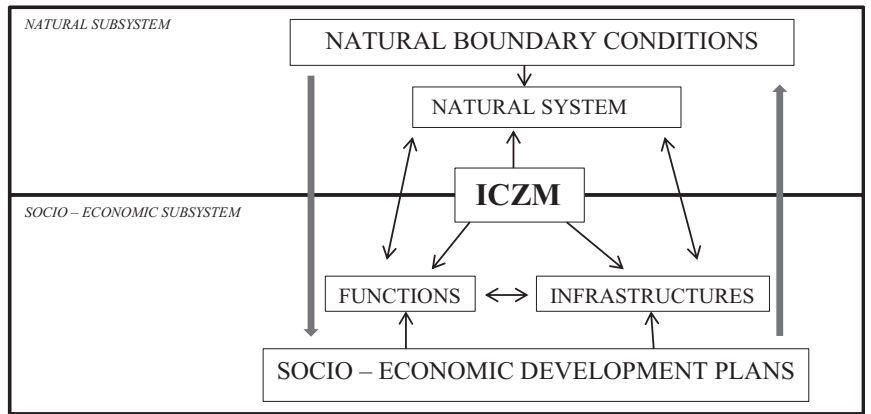

Fig. 1. A system view of a coastal zone in the Integrated Coastal Zone Management. From van der Weide, 1993, modified. involved in coastal management. Above all, in this work, it has been developed a definite GIS mapping of a regional coastal zone connecting two Sites of Community Interest (SIC), the terrestrial SIC "Monte Cocuzzo" (IT9310064) and the marine SIC "Scogli di Isca" (IT9310039) linked by the ecological and fluvial corridor of Verri stream basin (Fig. 2). The spatial mapping of these potential core areas of the Regional Ecological Network (Cantasano et al., 2012) and the broad extent of the catchment are represented in Fig. 2 that shows, on a graphic scale, the remarkable spatial connection between earth and water systems, as stated and recognized by Natura 2000 Network. This paper, first, presents the status of evaluation and the progress of ICZM in European countries and in the Mediterranean basin, highlighting the principle of an overall integration between terrestrial and marine environments through a new kind of landscape planning. Second, it analyzes the establishment and the implementation of this pattern in Italy where an effective ICZM meets a lot of problems caused by the lacking of a national plan and by the absolute absence of a system strategy. The third and last section illustrates an example of ICZM application in a study area located in southern Italy (Calabria region) through a methodological framework composed by functional analysis.

\section{Study area}

The study has regarded a coastal region marked by the presence of two Natura 2000 sites connected in the same landscape unit by Verri stream basin. The coastal stretch of about $3 \mathrm{~km}$ length, spreading along the Calabrian Tyrrhenian coast (Southern Italy), is a narrow and sandy beach exposed to erosion processes and partially protected by breakwaters. Just in the backlands, the littoral region is rather urbanized with the coastal towns of Belmonte Calabro (Cs) and Amantea (Cs) producing a slow but steady transformation in landscape use from agricultural to tourist and residential neighborhood. On this background, partially anthropic and natural, Verri stream originates from some springs rising to the surface at about $1.100 \mathrm{~m}$ a.s.l. on the slopes of Monte Cocuzzo. This waterway

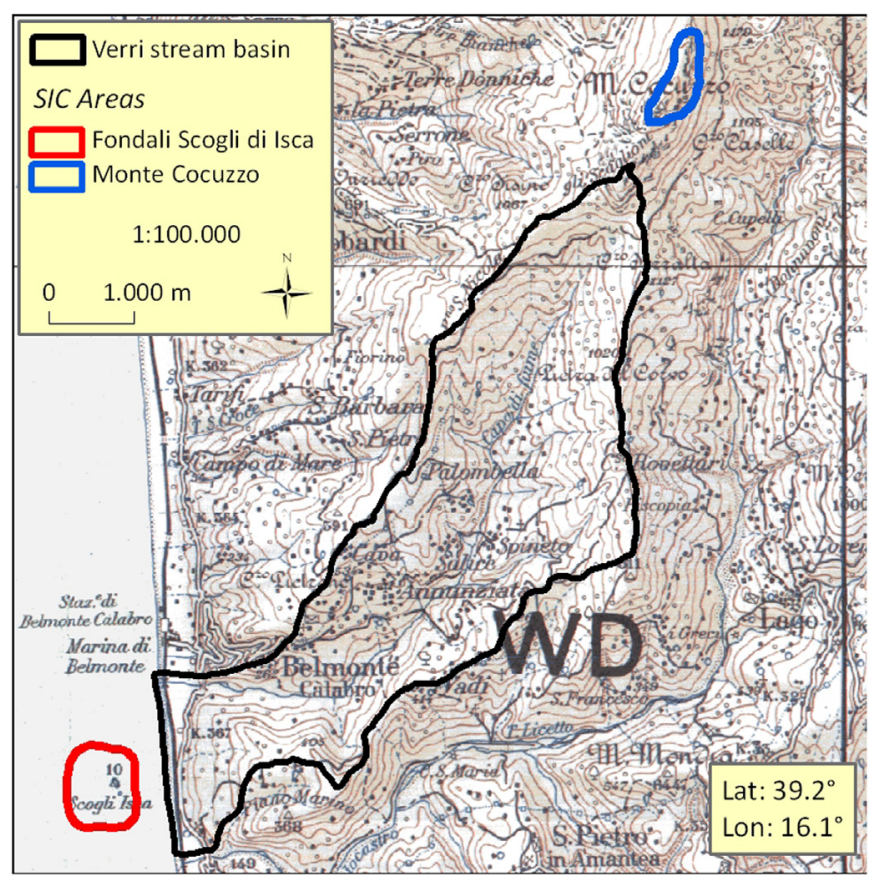

Fig. 2. Map of Isca coastal region with the terrestrial and marine SIC connected by the ecological and fluvial corridor of Verri stream basin. 
proceeds in south-southwest direction for an overall length of $9.5 \mathrm{~km}$ until its outlet to the Tyrrhenian Sea, just in front of the Marine Regional Park "Scogli di Isca". The catchment spreads out along an overall surface area of $23.9 \mathrm{~km}^{2}$, shows a mean slope of about $10 \%$ and a cuspidate shape. This coastal region has been, already, investigated by a research conducted by National Research Council (C.N.R.) - Institute for Agricultural and Forest Systems in the Mediterranean (I.S.A.Fo.M.) - Rende Research Unit, aimed to the evaluation of the ecological status of the basin. This first application of the Fluvial Functionality Index (IFF) (Callegari et al., $2008,2010)$ has established the good ecological status of the fluvial corridor, as highlighted in the relating mapping (Fig. 3).

In the Calabrian Region, with a coastline of $725 \mathrm{~km}$, coastal erosion is one of the most important issue for policy makers and a continuous problem for many littoral countries. This critical state is, mainly, caused by human pressures as:

- urbanization of coastline;

- removal of building materials from shorelines and coastal catchments;

- occupation and destruction of littoral dunes caused by human settlements;

- hydraulic and forestry arrangements along the hillsides of the catchments;

- development of transport networks in coastal regions.

In the studied area a confused landscape urbanization and an incorrect implementation of road and railway systems, running closed to the coastline, have produced a heavy coastal erosion and an increase of hydraulic hazards along inhabited coastal areas. By this way, it has been realized, since the 80's-90's until now, massive hard structures as breakwaters and artificial cliffs with a resulting poor nourishing of this coastal area and a general decay in shore ecosystem. Also the results of PAI (Hydrogeological Plan Asset), as stated by D.L. 180/98 and drawn up by the Regional Basin Authority (A.B.R.), confirm this negative trend assessing that all the coastline under study is subjected to erosional processes with a widespread coastal withdrawal so to arouse serious concerns about public safety. More generally, in the Calabria Region the wastewater management is, actually, committed to a joint venture, named SORICAL, with scanty results. Really, only the $37.4 \%$ of the regional population is properly served by an effective depurative system of secondary and tertiary levels and a lot of purification plans are old and in bad conditions or sometimes completely obsolete. The final outcome is that coastal waters are affected by outflow discharges loaded with pollutants and without any effective wastewater treatment. Finally, another problem completely disregarded by regional laws and, locally, by port authorities, is the heavy impact on marine ecosystems of another kind of pollution, by silting, caused by the dredging of sediment up drift in coastal waters.

\section{Methodology}

In order to measure the relationships between human activities and ecological features, it has been developed a methodological framework to assess the environmental quality of the coastal area surrounding Isca Marine Regional Park so to understand the linkages between coastal dynamics and social benefits arising from an effective plan of Integrated Coastal Zone Management of the studied area. The method, known as Function Analysis (hereafter

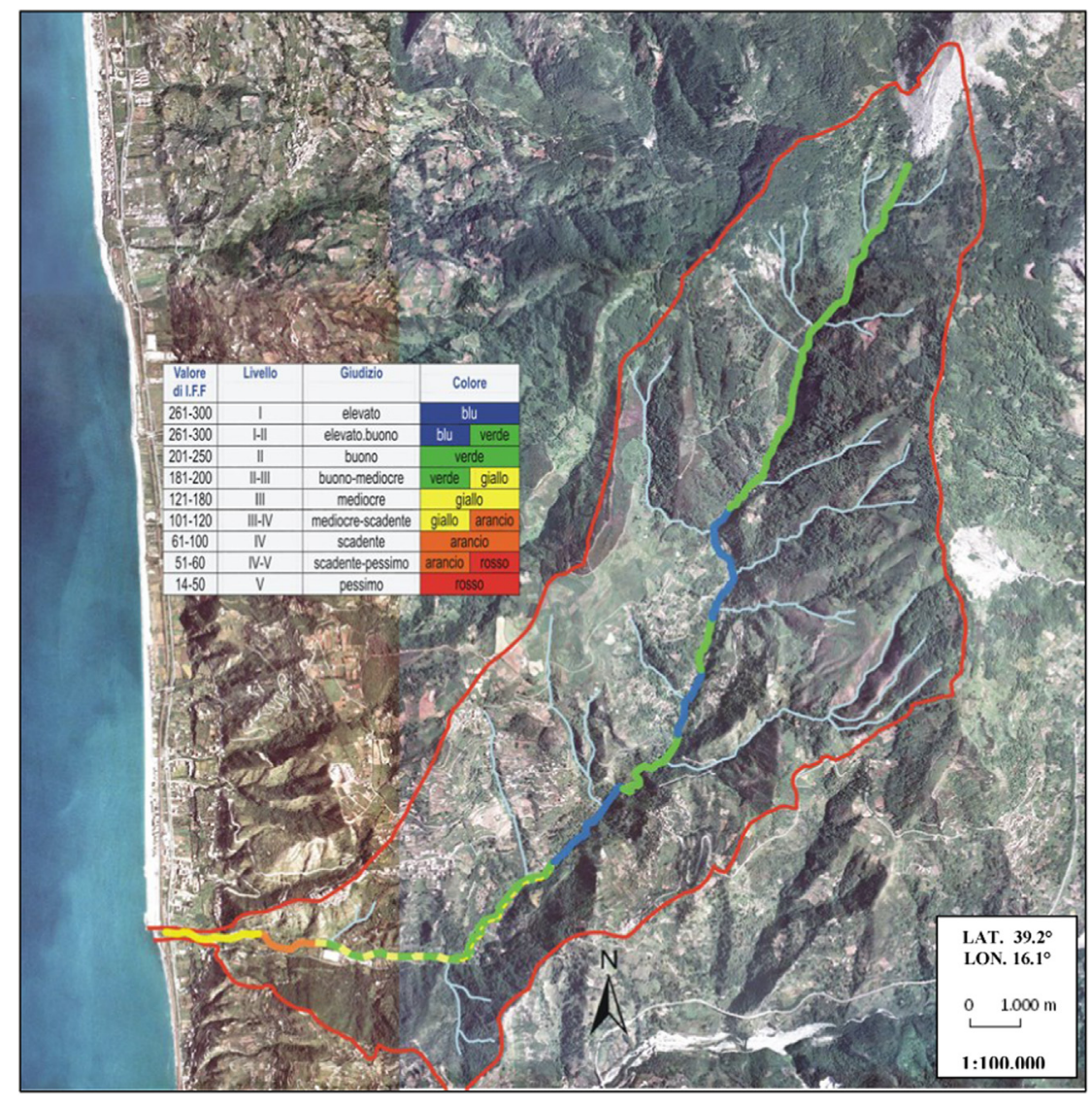

Fig. 3. Map of Fluvial Functionality Index (IFF) of Verri stream. 
FA), is based on a system of indicators that could be used to determine the quality of a coastal system and the potential development of the area by a scoring system (Cendrero and Fisher, 1997). Really, the fundamental role of FA has long been recognized worldwide by several authors as one of the best tools for enhancing coastal management (van der Maarel, 1979; de Groot, 1992; Cendrero and Fisher, 1997; van der Weide et al., 1999; Micallef, 2002; Phillips et al., 2007). This procedure follows the Cartesian principle to divide the complex and mixed landscape reality into single and different parts easier to analyze (Rivas et al., 1995). According to this effort, the coastal region is divided in three basic modules: environmental components, their features and individual indicator for each one (Table 1 ). The related values are expressed into a quality scale of $1-3$ and, afterward, combined to obtain an integrated environmental and social assessment (Micallef, 2002).

It is stated that normalized scores close to 1 correspond to good conditions of the indexes while values close to 0 highlight bad conditions. Then, it is estimated the total scores of ecological and socio-economic values dividing the collective score of these parameters by the total possible one. At last, the obtained data are plotted graphically in a diagram where the coastal zone studied is represented by a point in a bi-dimensional space (Fig. 4). In the graph, the $x$-coordinates show the potential development of the area while the $y$-coordinates point out its conservation value. Likewise, the $\mathrm{N}-\mathrm{P}$ diagonal becomes a conservation/development ratio while the $\mathrm{O}-\mathrm{Q}$ one represents its conflict gradient. So, in the diagram, the point position shows the development or the conservation potential of the coastal region. Indeed, points closer to the upper left corner would have a natural vocation for conservation actions while points closer to the lower right one would be suitable for human development. In particular, in the central part of the diagram, there is a conflict zone between potentials for development and/or conservation. So, this matrix enables to look after conservation or development potentials of coastal area because the unit position in the diagram can change with time showing the evolution of the seaboard system towards conservation or development states. However, each littoral zone needs specific options in coastal management and, therefore, different FA applications dealing with various aquatic environments. In this paper, it has been developed a specific FA for a coastal zone, located in a wilderness area, connecting two Sites of Community Interest (SIC) belonging to marine and terrestrial environments and linked by the ecological corridor of Verri stream basin. It has been applied this methodological framework evaluating specific indicators relevant to the studied area using, only, parameters representative for the coastal environment of the Marine Regional Park "Scogli di Isca". These numerical indices have been, particularly, fit to assess both environmental quality and development potential of an area characterized by high levels of conservation. The complex reality of this coastal region has been divided in four different ways distinguished in environmental and human components, their characteristics, the relative indicators and the final values. The scores of all indicators have been assigned into a quality scale ranging from 1 to 3 for each one by a scoring and weighting system, 1 and 3 being the lowest and highest values, respectively (Table 1 ). From this table have been selected the main environmental and human drivers that affect, more than others, the potential values of conservation and development represented in Fig. 4. Amongst the indicators, summarized in Table 1, are particularly important, for a correct coastal management of the studied area, the following parameters with their possible effects on coastal system:

1. Atmospheric depositions $>$ Scouring impact by water runoff and potential pollution by underground and freshwaters.
Table 1

Environmental and human components in the estimation of normalized scores of coastal parameters in the Marine Regional Park "Scogli di Isca".

\begin{tabular}{|c|c|c|c|}
\hline & Characteristics & Indicators & Values \\
\hline \multicolumn{4}{|l|}{ Environmental features } \\
\hline \multirow[t]{5}{*}{ Air } & Pollution & Gravity & 1 \\
\hline & & Visibility & 3 \\
\hline & & Effects on humans & 1 \\
\hline & Noise & Intensity & 1 \\
\hline & $\begin{array}{l}\text { Normalized } \\
\text { score }\end{array}$ & & 0.500 \\
\hline \multirow[t]{4}{*}{ Coastal waters } & Quality & Microbiological pollution & 2 \\
\hline & Aesthetic & Turbidity & 2 \\
\hline & conditions & Floating debris & 1 \\
\hline & $\begin{array}{l}\text { Normalized } \\
\text { score }\end{array}$ & & 0.555 \\
\hline \multirow[t]{2}{*}{ Freshwaters } & Supply & Rainfall & 3 \\
\hline & $\begin{array}{l}\text { Normalized } \\
\text { score }\end{array}$ & & 1.000 \\
\hline \multirow[t]{5}{*}{ Terrestrial biota } & Quantity & Natural vegetation cover & 3 \\
\hline & & Biological productivity & 2 \\
\hline & Diversity & Biological diversity & 3 \\
\hline & & Species of special interest & 3 \\
\hline & $\begin{array}{l}\text { Normalized } \\
\text { score }\end{array}$ & & 0.916 \\
\hline \multirow[t]{5}{*}{ Marine biota } & Quantity & Biomass & 1 \\
\hline & & Biological productivity & 1 \\
\hline & Diversity & Biological diversity & 3 \\
\hline & & Species of special interest & 3 \\
\hline & $\begin{array}{l}\text { Normalized } \\
\text { score }\end{array}$ & & 0.667 \\
\hline \multirow{3}{*}{$\begin{array}{l}\text { Geological and } \\
\text { topographical } \\
\text { features }\end{array}$} & & Lithological properties & 1 \\
\hline & & Size of bathing areas & 1 \\
\hline & $\begin{array}{l}\text { Normalized } \\
\text { score }\end{array}$ & & 0.333 \\
\hline \multirow[t]{7}{*}{ Hazards } & & Coastal erosion & 3 \\
\hline & & Coastal flooding & 3 \\
\hline & & Storms & 3 \\
\hline & & Coastline instability & 3 \\
\hline & & Soil erosion & 2 \\
\hline & & Torrential rains & 3 \\
\hline & $\begin{array}{l}\text { Normalized } \\
\text { score }\end{array}$ & & 0.944 \\
\hline \multirow[t]{5}{*}{ Resources } & $\begin{array}{l}\text { Non- } \\
\text { renewable }\end{array}$ & $\begin{array}{l}\text { Minerals, rocks, fuels, } \\
\text { construction materials }\end{array}$ & 3 \\
\hline & & Soil & 2 \\
\hline & Renewable & Fish & 1 \\
\hline & Landscape & Uniqueness & 3 \\
\hline & $\begin{array}{l}\text { Normalized } \\
\text { score }\end{array}$ & & 0.750 \\
\hline Total ecological value & & & 61 \\
\hline Normalized score of & & & 0.726 \\
\hline
\end{tabular}

ecological value

Human features

Social values

Potential

Historic, artistic sites

Public recreation facilities

Hotels, restaurants

Parking

Accessibility

Land use

Extend of development

Population density

Intensity of use

Extent of reclamation

Public health

Employment chances

Environmental quality

Total social value

Normalized score of

social value

Note: Value allocations for environmental and human indicators ranging from $1=$ minimum to $3=$ maximum.

From Micallef and Williams, 2003; modified. 


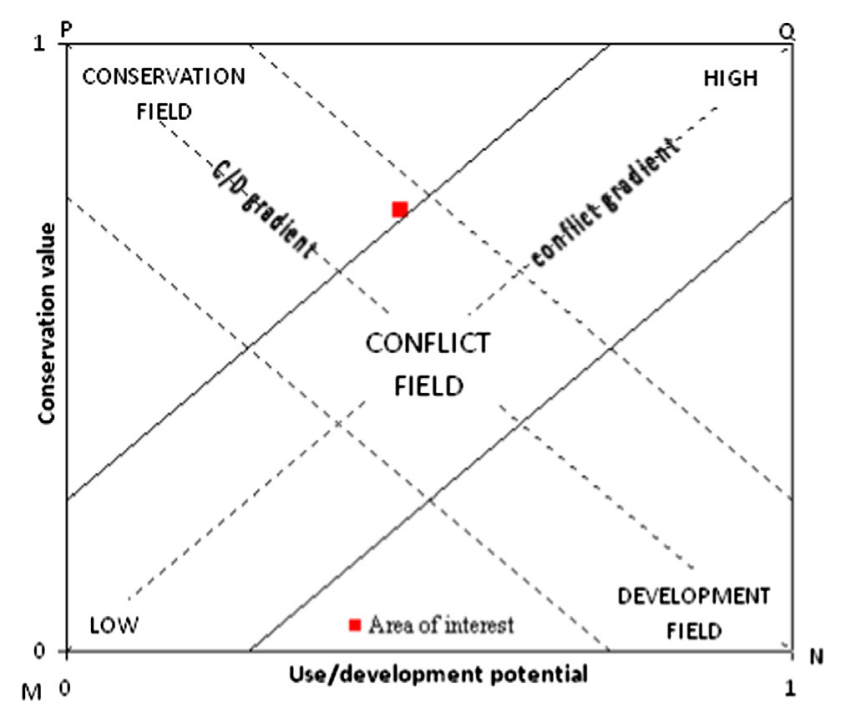

Fig. 4. Diagram of conservation-development potential in Isca coastal region.

2. Natural vegetation cover $>$ Fixation of solar energy and biomass production.

3. Biological diversity of terrestrial and marine biota $>$ maintenance and equilibrium of biological and genetic diversity.

4. Hazard conditions of the coastline $>$ Coastal and soil erosion.

5. State of non-renewable resources $>$ Exploitation of mineral resources, construction materials and fuels.

6. Accommodation facilities for tourist $>$ Touristic pressure on natural resources.

Then, it has been normalized the total score of the ecological and social values to give a final score between 0 and 1 , carried out by dividing the collective value of the parameters by the total possible score. The final values of ecological and social parameters are expressed using a $0-1$ scale with the maximum theoretical value of 1 corresponding to the best environmental and social conditions and the minimum of 0 proportionate to the worst state. Finally, in the second step of the procedure, ecological and human values have been plotted in a diagram (Fig. 4) where the studied area has been represented by a point in a two-dimensional space to identify whether area is within conservation, development or conflict zones. In the end, the FA framework suggests a set of different environmental indices useful to measure and to establish the environmental quality of coastal environments, taking into account both natural and human characteristics of the system and monitoring its changes with time, so to improve an effective integration between scientific assessments and landscape planning into decision-making processes.

\section{The Integrated Coastal Zone Management in European and Mediterranean regions}

The integration between terrestrial and marine environments is the main purpose in the implementation of ICZM in European countries and in the Mediterranean basin. This idea of a joint outlook of coastal system is the leading principle to direct European policy in the management of their coastlines according to a multiple approach (EC, 2006). The main objective of this politics is to maintain or to achieve a "good ecological status" for waters, habitats and marine resources through a common strategy based on an integrated ecosystem approach for the environmental monitoring of European waters (Borja et al., 2010). The leading laws, addressing the European policy for ICZM, is the Recommendation 2002/413/EC in which European Union asks Member States (EC, 1999, 2001, 2002) to accept national strategies for coastal management according to ICZM principles (McKenna et al., 2008):

1. Support and involvement of local, regional and national governments.

2. Use of a set of instruments to facilitate an agreement between sectorial policy objectives and coastal management respecting the principles of a sustainable development.

3. A broad and overall perspective in the management of European coastlines taking into account the connections and the differences between natural systems and human activities impacting coastal areas.

4. A long-term perspective according to the precautionary principle and to the needs of present and future generations.

5. Knowledge of natural processes and respect for the carrying capacities of coastal ecosystems, to make human activities environmentally sustainable in the long run.

6. Adaptive management of coastal areas in a gradual process facilitating the solution of problems and the advances in scientific knowledge.

7. Adoption of specific solutions and flexible measures linked to local needs.

8. Involvement of all parties concerned coming from political, social, economic and scientific sectors in the management process.

In this framework, the regionalization of environmental laws, on a Mediterranean scale, is one of the most important action lines of Community policy (Hayward, 1984). In European countries, the ICZM implementation has been marked, in these last decades, by an increasing interest towards regional sea patterns (Rochette and Billé, 2012). This trend has been highlighted through the Mediterranean ICZM Protocol, which represents, until now, the first and only legal instrument specifically aimed at a coastal zone management in the basin (UNEP, 2008). The Protocol reflects this regional approach in the protection of Mediterranean countries and establishes a legal support for the sustainable development of its coastal zones (Koutrakis et al., 2011). Really, the Mediterranean area could perform a leading role to address the ICZM implementation within the framework of the Mediterranean Action Plan (MAP) signed by 21 European countries in Barcelona and adopted in 1975 at the Intergovernmental Meeting of the Mediterranean Coastal States (IUCN, 1975). However, big problems still exist for a real and effective ICZM implementation in some Mediterranean countries enable to join a timely coastal zone development with the principles of biodiversity conservation, as stated by the lacking achievement of ICZM in the Mediterranean basin (Fig. 5). This critical state is even more serious considering that, in Mediterranean countries, the coastal population accounts for $10 \%$ of the total one and the demographic projection for 2025 a.d. expect a population increase varying from 160 to 210 million inhabitants on coastal areas (Cori, 1999). Besides, there is a considerable trend in the Mediterranean coastal settlement system implying an increase in the number of second houses along the national coastlines. Other human pressures, such as tourism, industry, traffic and changes in land use, imply a growing demand on coastal resources and serious environmental effects on the sensitive and unstable littoral balance (Pavasovic, 1996). So, it is necessary a sound marine policy for the prevention and the control of these activities through a new spatial planning of the coastal areas. This landscape approach should be, really, extended landwards from marine ecosystems to coastlines until continental areas along the ideal lines of the regional catchments, that represent the main common link in coastal systems. 


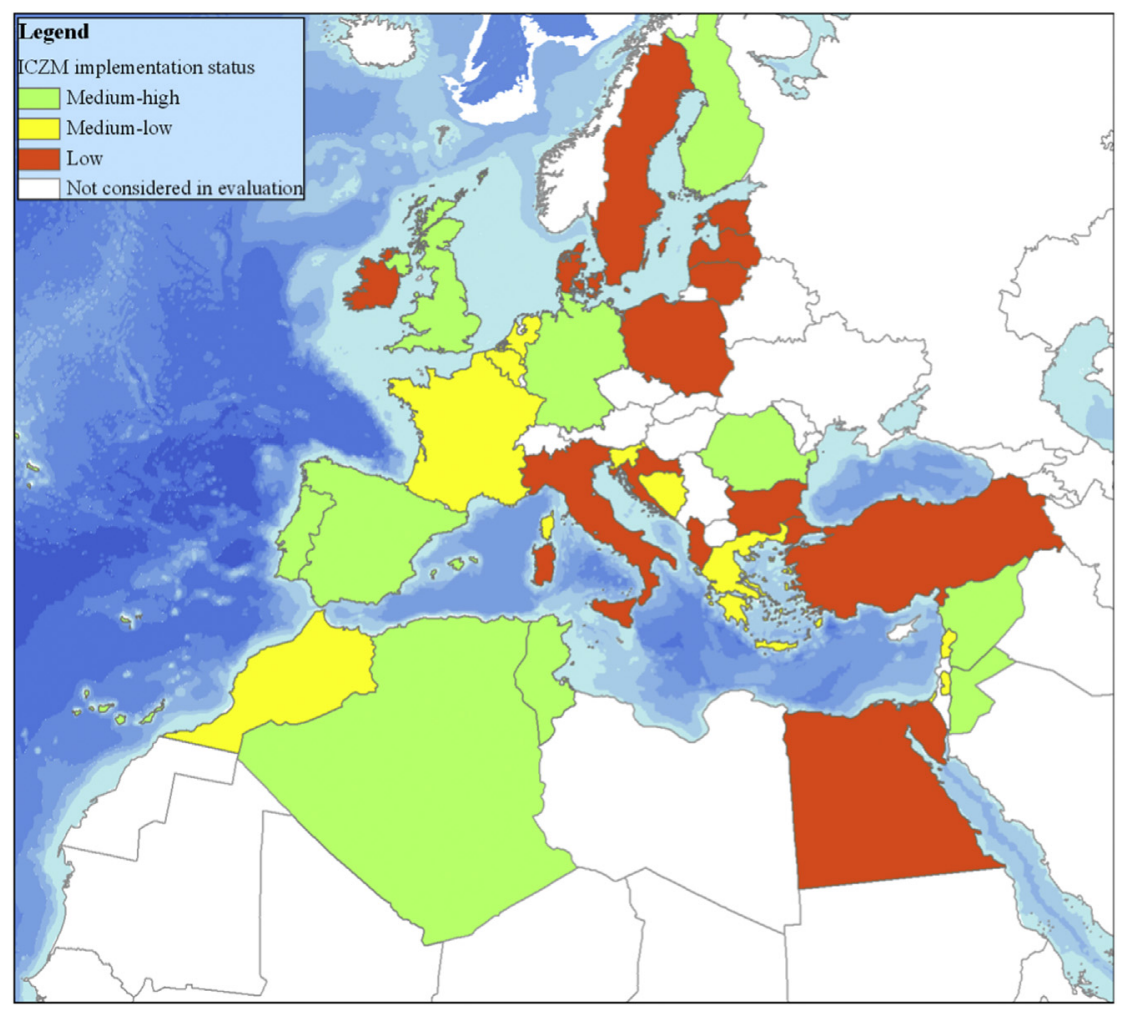

Fig. 5. ICZM implementation status in European and Mediterranean countries.

\section{The Italian framework}

Italy is one of the most important European coastal countries with a coastline of $7.375 \mathrm{Km}$ but, also being the sixth European region in littoral extension (Fig. 6), it suffers, nowadays, the negative consequences of a wrong coastal management in which private and personal business have prevailed on the common good. Today, the erosion process and the growing building pressure along Italian coastline are serious problems together with other issues as coastal pollution and biodiversity loss. These environmental questions must be, urgently, solved to direct this country towards a sustainable management of its coastal areas. In Italy, coastal management has been perceived as a key issue, only from the 1990s, about two decades after the early U.S. experiences (U.S. Commission on Marine Science, 1969). Really, the first national effort has been adopted in 1982 with the law n.979 on sea protection drawn up to

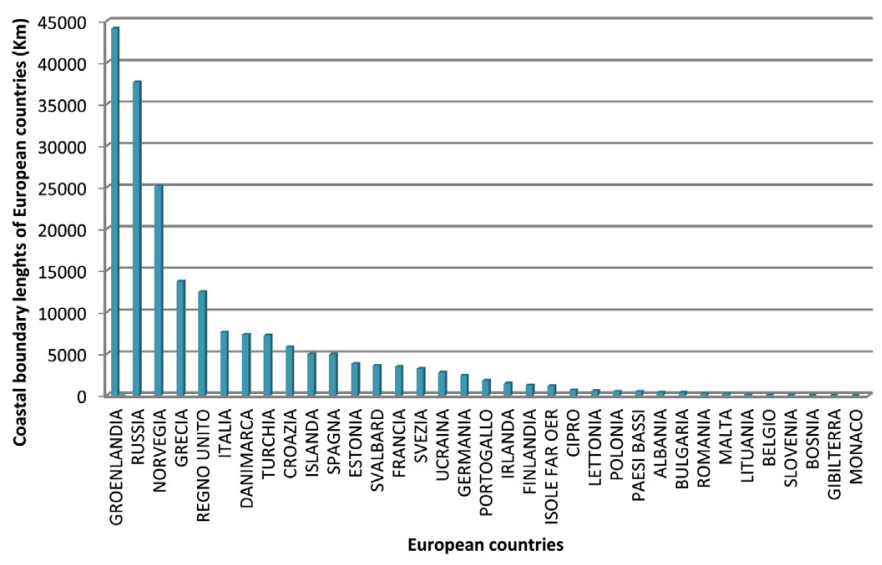

Fig. 6. Coastal development of European countries. limit the marine pollution and to establish the national Marine Protected Areas (MPA). After that time, Italian state has taken further important steps such as the Decrees n.152/2006 and n. 190/ 2010 conforming to previous Directives issued by European Union. So, the Italian coastal management should be aimed at:

1. Achievement of a "good ecological status" for national coastal waters within 31/12/2015.

2. Total accomplishment of UE Directive n.56/2008 expressing a common action for marine environments.

3. Processing and accomplishment of a national strategy for an effective Integrated Coastal Zone Management.

4. Implementation of management plans on seaboard as stated by the Decree n. 152/2006.

5. Approval and enforcement of the National Protocol on ICZM.

However, this complex set of rules, seemingly complete, has met some problems that constitute, until now, obstacles in the real implementation of the national program provided for by law. The greater gaps, preventing an effective ICZM application on Italian coastal boundaries, are:

a) connecting problems between the different coastal areas involved in the ICZM implementation;

b) gaps in the involvement power of local administrations;

c) lack of planning instruments in coastal management;

d) problems in making effective the legal instruments;

e) lack of ICZM projects on a national scale;

f) fragmentation of institutional arrangements between administrative levels;

g) shortage of a system strategy.

In this deadlock, due to the persistent inertia of State authorities, the first ICZM initiatives, for a sustainable development of coastal 
areas, have been realized locally to compensate the shortcomings of a national planning (Rochette, 2009). These regional experiments have been started up and sometimes, developed in some Italian regions such as: Emilia-Romagna (2005), Toscana (2004), Abruzzo (2003), Marche (2005), Sardegna (2007), Liguria (2002) and Lazio (2008). So, it is to be hoped that the implementation of these regional plans could compel Italian state to an effective protection of our national coastal zones through a political process that could be realized in a bottom-up trend.

\section{A pattern of coastal management in Calabria}

The data analysis, pointed out in the table (Table 1), highlights the good environmental condition of the littoral zone but show, all the same, a definite human pressure existing on the whole coastal region. The area of interest, located at the figure's left quadrant but close to the conflict zone should be addressed to an appropriate management strategy by achieving a balance between development and conservation programs. Really, parameters and indicators, used for the evaluation of conservation/development status of the studied area, can vary with time and, therefore, the unit position in the diagram is changeable moving towards $\mathrm{P}$ or $\mathrm{N}$ corners and evolving in conservation or development states. However, it is hoped for addressing the area to high level of protection through conservation programs because in this coastal region, of high environmental value, are located a Marine Regional Park and two Sites of Community Interest. In conclusion, FA provides the basis to establish the environmental level of this wilderness area looking after its evolution in order to adjust planning and management policies to local conditions with the firm belief that conservation is the higher priority for this coastal region. So, the Marine Regional Park "Scogli di Isca" could be an ideal pattern where the main principle to connect different ecosystems in the same landscape unit should be combined with a planning process and an overall landscape management.

\section{Conclusions}

Coastal zone is a focal area on the border between land and sea. These two systems, different one each other, protect goods of great value for all mankind but these resources look, today, rather limited and, so, must be retained on both sides of this line. Then, coastal environment requires an integrated management, so to establish strong interactions between the different elements acting on coastal areas. The main principles of this new approach are (Suman et al., 2005):

- human components made by the local communities living in coastal regions;

- policy makers and coastal managers whose decisions affect the behavior of local people;

- scientific community, made up by environmental and social scientists, addressing the choices in coastal management.

The central role of ICZM lies into managing coastal and terrestrial resources through a coordinated strategy in which coastal waters and continental areas are inserted in the same landscape unit, represented in the following pattern (Fig. 7). So, ICZM process has emerged as the most appropriate tool for preserving natural resources such as sandy beaches, coastal dunes, Posidonia oceanica meadows, riparian woods and, more generally, marine and fluvial biota. Really, to protect these valuable elements, terrestrial and aquatic environments must be managed altogether in the same joining program. This model could be the drawing force to support

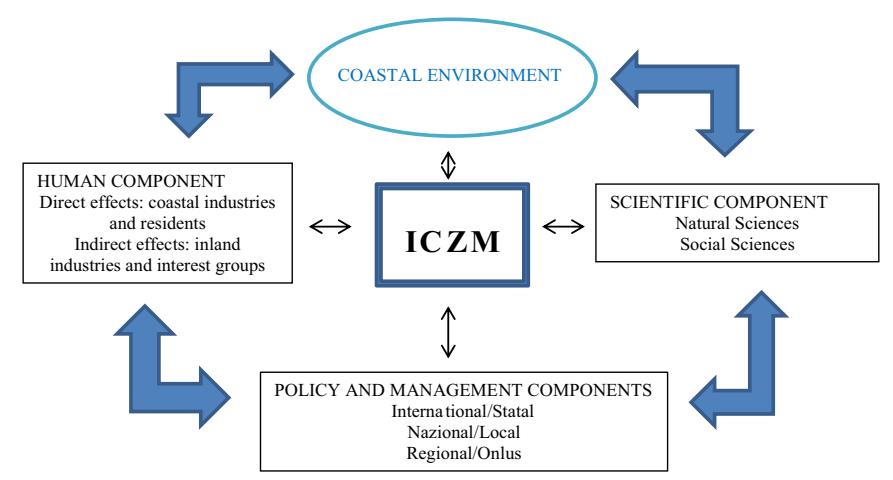

Fig. 7. Coastal pattern in ICZM process. From Suman et al., 2005, modified.

coastal biodiversity, to solve human demands on natural resources and to achieve a sustainable development of the coastal zone.

In southern Italy and, especially, in the Calabria region, coastal and river systems could be the main landscape units in coastal management as both biotopes support a whole of ecological and social functions depending on the strong linkages between littoral and catchment areas. Really, coastal environments, including terrestrial, freshwater and marine ecosystems exemplify the general concept of "open systems" for the continuous exchange of materials and energy between them (Reiners and Driese, 2001). Indeed, different human activities, within the deposit area of the basins could benefit from the natural resources coming from the transport and supply zones of the catchments while aquatic ecosystems are, clearly, affected by what happened in the surrounding uplands. So, the dynamic equilibrium of coastal regions needs an integrated and multiple approaches able to consider ecological, social and economic features as integral parts of a whole system. Really, this comprehensive view in the coastal management must include in the same landscape unit the littoral and catchment areas because human pressures on these regions can affect coastal landscapes and vice versa. In this open system, changes in land and resource uses in the transport or in the supply zones of the catchments, by both sides of fluvial corridors, are reflected downstairs, until coastal waters, affecting the integrity of marine ecosystems. Therefore, in Calabria it is suggested a new kind of conservation approach for an integrated management of coastal areas and river basins, according to ICARM pattern (Integrated Coastal Areas and River basin Management) (UNCHS, 1996), as shown in the following model (Fig. 8). This framework establishes the goals, the policies and the management

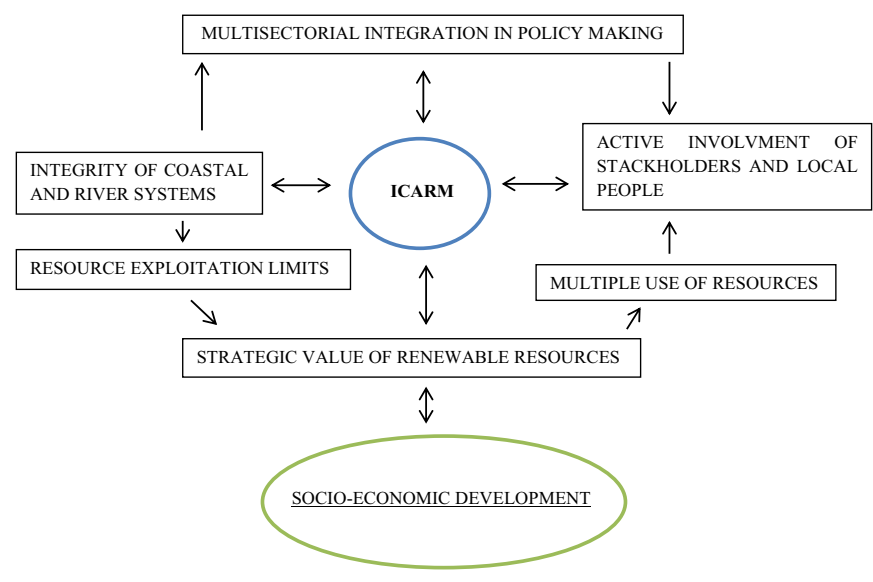

Fig. 8. ICARM pattern in the integrated management of a coastal region. 
options based on the relationships between coastal and river systems within the main principles of a sustainable development. The general objectives of ICARM model are (Coccosis, 2004):

- develop human resources and institutional capacities;

- support participation of all actors involved from public and private sectors;

- protect and improve traditional uses and cultural heritage;

- reduce risks to vulnerable resources;

- identify natural resources utilizable without exceeding their rate of replenishment;

- ensure the integrity of marine and river ecosystems;

- respect the natural dynamic processes.

The application of FA framework in the coastal region of Isca Marine Regional Park shows its good environmental condition but highlights, at the same time, the heavy urbanization and the large extension of urban development along its coastline, Indeed, the increasing human impact on these natural landscapes has produced conditions of environmental decay and a reduction of life quality for local people, as highlighted by FA analysis. However in this littoral area of high environmental value, characterized by the presence of two important Sites of Community Interest (SIC), it is necessary to realize an effective matching between anthropogenic pressures and conservation plans. So, environmental protection and human development should occur through ICZM programs in a working and continuous process to promote a dynamic equilibrium between economic growth, human use of natural resources and environmental protection of coastal ecosystems. Really, in the complex environmental pattern of Isca Marine Regional Park, an overall planning between marine and terrestrial systems could achieve in time an effective landscape improvement and a real socioeconomical interaction in a landscape connectivity related to local economies. Besides, environmental protection and tourist vocation of this coastal environment could be an important spur to direct a large number of visitors from the Marine Protected Area to the close catchment of Verri stream producing economic benefits for locals and new profit-bearing investments in tourist trade (Cantasano et al., 2012). The expected outcome of this patchwork, based on integration and participation processes, would be the optimization of policy interventions to reduce potential conflicts and to strengthen collaborations between different management levels appreciating the linkages between coastal and river systems and promoting the social and economic development of local communities. In the end, integration is the key-word to coordinate all the initiatives at public and private levels toward a long term outcome of coastal resources.

\section{Acknowledgments}

We greatly appreciate the extensive comments from two anonymous referees for their useful comments and suggestions which have improved this manuscript.

\section{References}

Barcena, A., 1992. An overview of the oceans in agenda 21 of the 1992 united nations conference on environment and development. Mar. Pollut. Bull. 25, $107-$ 111.

Borja, A., Dauer, D.M., Elliott, M., Simenstad, C., 2010. Medium and long-term recovery of estuarine and coastal ecosystems: patterns, rates and restoration effectiveness. Estuar. Coasts 33, 1249-1260.

Callegari, G., Cantasano, N., Froio, R., Ricca, N., Veltri, A., 2008. L'indice di Funzionalità Fluviale: un approccio metodolologico in Calabria. In: Giornata Mondiale Dell'acqua 2008. Accademia Nazionale dei Lincei, Roma.

Callegari, G., Cantasano, N., Froio, R., Ricca, N., Veltri, A., 2010. Un'applicazione dell'indice di funzionalità fluviale. Il caso studio del torrente Verri. Quad. Idron. Mont. 29 (2), 139-155.
Cantasano, N., Callegari, G., Veltri, A., Bulgarini, F., 2012. Reti ecologiche e corridoi fluviali in Calabria. Territori 9, 44-57.

Cendrero, A., Fischer, D.W., 1997. A procedure for assessing the environmental quality of coastal areas for planning and management. J. Coast. Res. 13 (3), 732-744.

Cicin-Sain, B., Belfiore, S., 2005. Linking marine protected areas to integrated coastal and ocean management: a review of theory and practice. Ocean Coast. Manage. 48, 847-868.

Coccossis, H., 2004. Integrated coastal management and river basin management. Water Air Soil Poll. Focus 4, 411-419.

Cori, B., 1999. Spatial dynamics of Mediterranean coastal regions. J. Coast. Conserv. $5,105-112$.

Courtney, C.A., White, A.T., 2000. Integrated costal management in the Philippines: testing new paradigms. Coast. Manage. 28, 39-53.

de Groot, R.S., 1992. Functions of Nature. Evaluation of Nature Environmental Planning, Managing and Decision Making. Allen \& Unwin, London.

European Commission, 1999. Towards a European Integrated Coastal Zone Management (ICZM) Strategy: General Principles and Policy Options. Office for Official Publications of the European Communities, Luxembourg, pp. 1-35.

European Commission, 2001. EU Focus on Coastal Zones. Office for Official Publications of the European Communities, Luxembourg, pp. 1-29.

European Commission, 2006. Green Paper: Towards a Future Maritime Policy for the Union: A European Vision for the Oceans and Seas. Bruxelles [online]. Available from: http://ec.europa.eu/maritimeafairs/pdf/greenpaper_brochure_en.pdf.

European Parliament and Council, 2002. Towards Environmental Performance Indicators for the European Union (EU). A European System of Environmental Indicators. First Publication. Bruxelles [online]. Available from: http://www.e$\mathrm{m}$-a-i-l.nu/tepi/firstpub.htm.

Hayward, P., 1984. Environmental protection: regional approaches. Mar. Policy 8 (2), $106-119$.

IUCN, 1975. International conference on marine parks and reserves: recommendations. Spl. Suppl. IUCN Bull. 6 (7)

Kelleher, G., Kenchington, R., 1990. Guidelines for the Establishment of Marine Protected Areas. World Conservation Union, Gland, pp. 1-79.

Koutrakis, E., Sapounidis, A., Marzetti, S., Marin, V., Roussel, S., Martino, S. Fabiano, M., Paoli, C., Rey-Valette, H., Povh, D., Malvárez, C.G., 2011. ICZM and coastal defence perception by beach users: lessons from the Mediterranean coastal area. Ocean Coast. Manage. 54, 821-830.

Micallef, A., 2002. Bathing Area Management in the Maltese Islands. Unpublished $\mathrm{PhD}$ thesis. University of Wales, Swansea.

Micallef, A., Williams, A.T., 2003. Application of function analysis to bathing areas in the Maltese islands. J. Coast. Conserv. 9 (2), 147-158.

McKenna, J., Cooper, A., O'Hagan, A.M., 2008. Managing by principle: a critical analysis of the European principles of integrated coastal zone management (ICZM). Mar. Policy 32, 941-955.

McLeod, K., Leslie, H., 2009. Ecosystem-based Management for the Oceans. Island Press, Washington, p. 368

Olsen, S., Christie, P., 2000. What are we learning from tropical coastal management experience? Coast. Manage. 28, 5-18.

Pavasovic, A., 1996. The Mediterranean action plan, phase II and the revised Barcelona Convention. Ocean Coast. Manage. 31, 133-182.

Phillips, M.R., Abraham, E.J., Williams, A.T., House, C.H., 2007. Sustainability and function analysis as a management tool: the South Wales (UK) coastline. J. Coast. Conserv. Manage. 11, 159-170.

Reiners, W.A., Driese, K.L., 2001. The propagation of ecological influences through heterogeneous environmental space. Bio-Science 51, 939-950.

Rivas, V., Rix, K., Frances, E., Cendrero, A., Brunsden, D., 1995. The use of indicators for the assessment of environmental impacts on geomorphological features. Quad. Geolog. Alpina Quater. 3, 157-180.

Rochette, J., 2009. Challenge, dialogue, action... recent developments in the protection of coastal zones in Italy. J. Coast. Conserv. 13, 131-139.

Rochette, J., Billé, R., 2012. ICZM protocols to regional seas conventions: what? why? How? Mar. Policy 36, 977-984

Suman, D., Guerzoni, S., Molinaroli, E., 2005. Integrated coastal management in the Venice lagoon and its watershed. Hydrobiologia 550, 251-269.

U.N., 1992. United Nations Conference on Environment \& Development. Agenda 21 (Chapter 17).

U.N.C.H.S. (United Nations Centre for Human Settlements Habitat), 1996. Issues in the Integrated Planning and Management of River/Lake Basins and Coastal Areas, pp. 1-57. A Human Perspective, Nairobi.

UNEP/MAP/PAP, 2008. Protocol on Integrated Coastal Zone Management in the Mediterranean, pp. 1-89.

U.S. Commission on Marine Science, 1969. Our Nation and the Sea. A Plan for National Action. Report of the Commission on Marine Science, Engineering and Resources. United States Government Printing Office, Washington, p. 305.

van der Maarel, E., 1979. Environmental management of coastal dunes in the Netherlands. In: Jefferies, R.L., Davy, A.J. (Eds.), Ecological Processes in Coastal Environments. Blackwell, Oxford, pp. 543-570.

van der Weide, 1993. A system view of integrated coastal management. Ocean Coast. Manage. 21, 129-148.

van der Weide, J., van der Meulen, F., Sarf, F., Gengic, S., Gabunia, M., 1999. Assessing the value of two coastal wetlands in Turkey. In: Ozahan, E. (Ed.), MedCoast '99 Joint Conference on Land-ocean Interactions: Managing Coastal Ecosystems. MedCoast Secretariat, Ankara, pp. 1009-1020. 